\title{
Giant fibrovascular polyp of the oesophagus: report of a case and effects on oesophageal function
}

\author{
R PENAGINI, T RANZI, P VELIO, P ZANNINI, G NEGRI, G PEZZUOLI, \\ AND P A BIANCHI \\ From the Cattedra di Patologia Medica III, Istituto di Scienze Mediche and Istituto di Clinica Chirurgica I, \\ University of Milan, Italy
}

SUMmıRY A 40 year old man with dysphagia and a giant fibrovascular polyp of the oesophagus is reported. The patient was followed for two years before removal of the polyp. During this period the tumour markedly increased in size and the oesophagus reached a maximum diameter of $5.9 \mathrm{~cm}$. In presence of the polyp the body of the oesophagus had no pressure activity after swallows and a 22 hour intraoesophageal $\mathrm{pH}$ record showed $\mathrm{pH}>\mathbf{7}$ for $31 \cdot 4 \%$ of the time and never $\mathrm{pH}<4$. After excision of the tumour the oesophagus regained normal size and peristalsis. Intraoesophageal pH $>7$ and $<4$ were recorded for $1 \cdot 6 \%$ and $16 \cdot 1 \%$ of the time respectively. Dysmotility was probably a contributing factor to the genesis of dysphagia induced by the giant fibrovascular polyp. Prolonged alkalinisation of intraoesophageal pH conceivably reflected altered oesophageal clearing of alkaline salivary and/or oesophageal secretions.

Benign tumours of the oesophagus are uncommon. ${ }^{1-;}$ They are mainly leiomyomas, but fibrovascular polyps, although much rarer, were known to physicians even before the use of radiology and endoscopy ${ }^{+-}$as they are sometimes regurgitated into the mouth. Not infrequently fibrovascular polyps pose diagnostic problems especially when they attain giant proportions, being confused most commonly with achalasia and non-pedunculated intramural tumours. ${ }^{-3(-11}$ Fibrovascular polyps have been described with different names such as pedunculated fibromas, fibrolipomas, lipomas, myxofibromas and

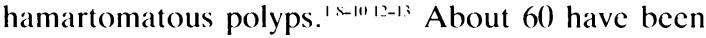
reported ${ }^{1-1:}$ to date, which developed almost exclusively in the cervical ocsophagus at the level of the cricoid cartilage. It is commonly thought ${ }^{315}$ that the symptoms induced by these polyps are caused by mechanical obstruction, however, there are no data regarding their possible influence on ocsophageal motor function. We report the case of a man

Address for correspondence: Dr R Penagini. (attedra di Patologia Mledica III

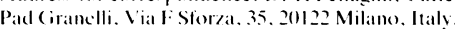

Accepted for publication 14 March loses with a giant fibrovascular polyp of the oesophagus causing severe dysphagia, in whom oesophageal motility and 22 hour intraoesophageal $\mathrm{pH}$ monitoring were performed before and four months after excision of the tumour.

Case report

A 40 year old man was referred to our outpatients' clinic in July 1986 with a 10 day history of dysphagia, odynophagia and a sensation of a lump in the throat. At that time the patient was able to follow a semiliquid diet only.

His past medical history included anxiety and chest oppression, the latter being considered a psychosomatic symptom. A barium meal done in 1973 for postprandial heartburn was apparently normal (Fig. 1a).

Physical cxamination and routine blood tests were unremarkable. A barium swallow was done immediately and showed (Fig. 1b) a dilated oesophagus (maximum diameter $4.5 \mathrm{~cm}$ ) containing a large filling defect extending from the neck to a few $\mathrm{cm}$ above the cardia. At upper gastrointestinal 

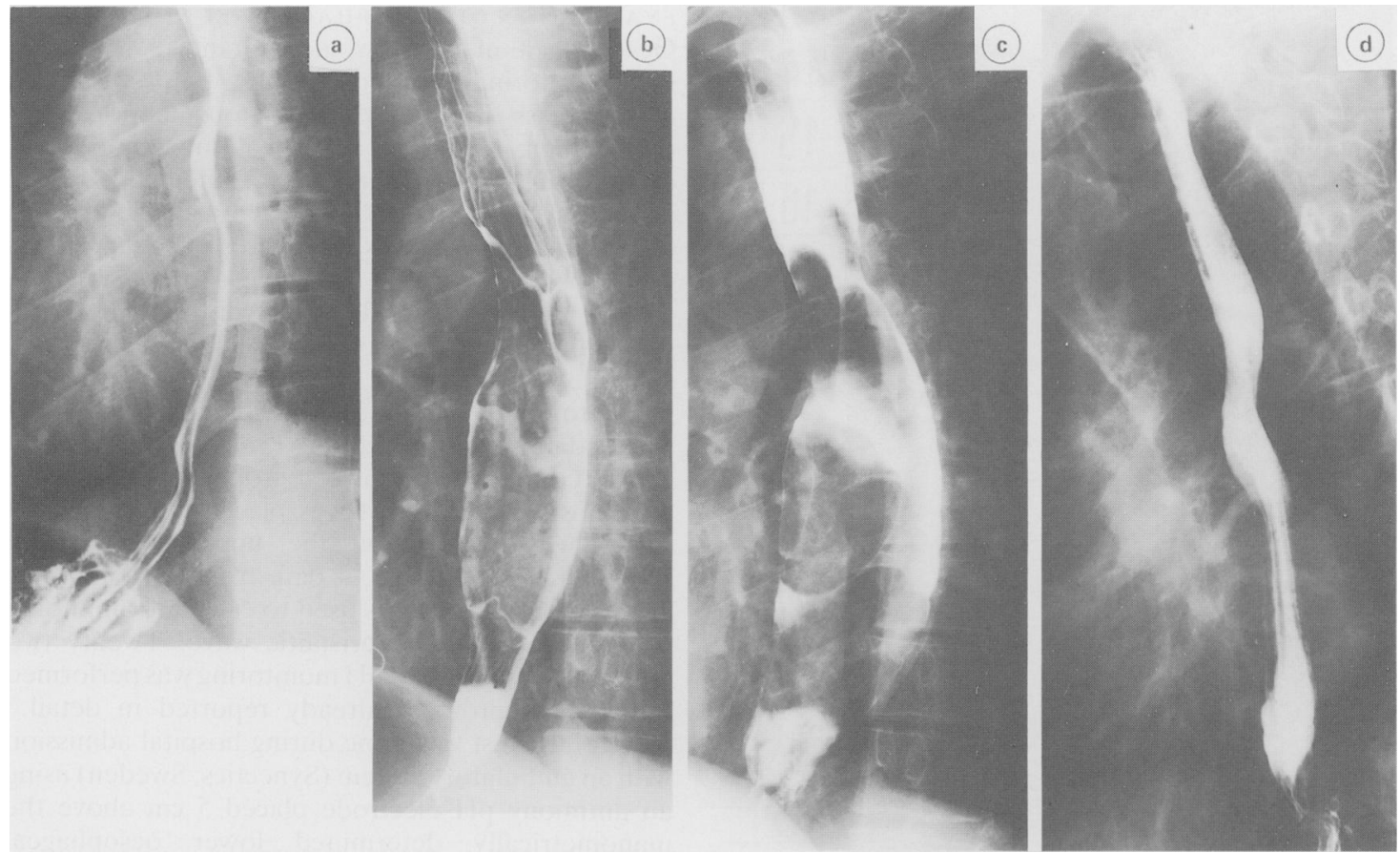

Fig. 1 Barium swallows: (a) in 1973; (b) in 1986, at presentation; (c) in 1988, before excision of the polyp; (d) in 1988, four months after excision of the polyp. Note the progressive dilatation of the oesophagus before excision of the polvp and return to a normal size four months after excision.

endoscopy a mass was identified which started immediately below the upper oesophageal sphincter, extended up to 7-8 $\mathrm{cm}$ from the cardia, was covered with normal mucosa, and appeared progressively larger as the scope moved distally. The mucosa of the distal $3 \mathrm{~cm}$ of the ocsophagus showed erosive oesophagitis. The patient refused any further investigations or surgery. His symptoms fluctuated, but worsened progressively and he lost $10 \mathrm{~kg}$ in weight up to May 1988 when he agreed to be further investigated and eventually to have his mass removed. At this time his blood tests showed an ESR of 108 , Hb $11 \cdot 3$ $\mathrm{g} / \mathrm{dl}$, WBC $11300 / \mathrm{mm}^{3}$, platelets $410000 / \mathrm{mm}^{3}$ and raised $\alpha_{2}$ globulins. A repeated barium swallow showed (Fig. 1c) a substantial growth of the mass (maximum diameter of the oesophagus $5.9 \mathrm{~cm}$ ). An upper gastrointestinal endoscopy showed the mass to extend up to $3 \mathrm{~cm}$ from the cardia. To clarify the nature of the tumour a computed tomography (CT) scan of the neck and chest (Fig. 2) was then performed which showed a mass of homogeneous density, comparable to density of the lax connective tissue, which did not infiltrate the oesophageal wall nor compressed the trachea. A magnetic resonance imaging (MRI) scan was also done which did not add any information to the computed tomography. After barium swallow, endoscopy, computed tomography and magnetic resonance imaging scans, it remained

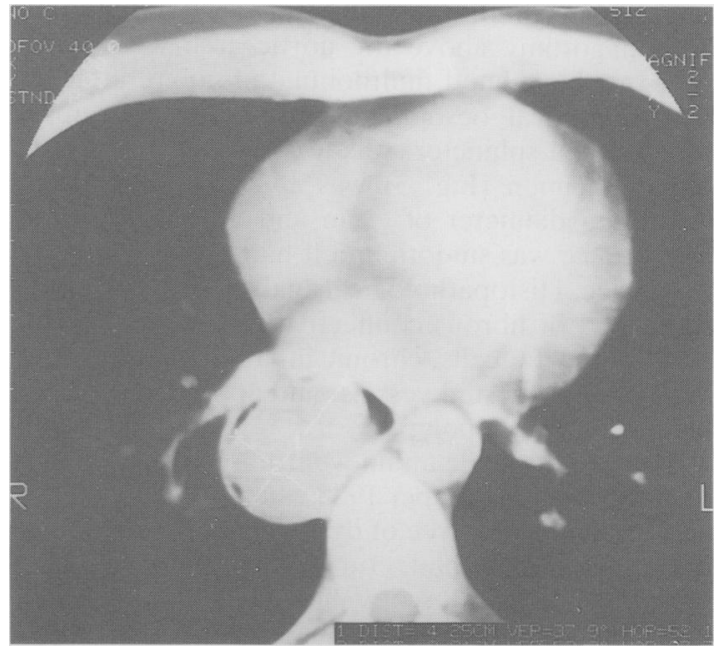

Fig. 2 Computerised tomogram of the chest showing an apparenty intramural mass within the oesophagus. 


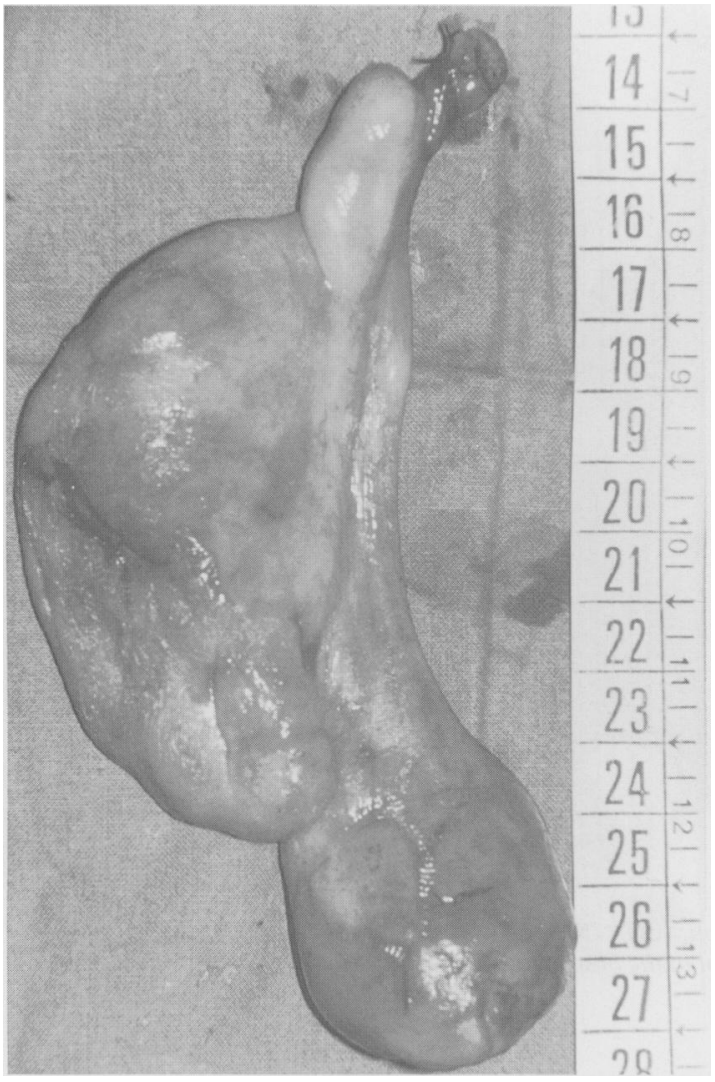

Fig. 3 (iross specimen of the polyp.

unclear whether the mass was intraluminal or intramural. On June 16, 1988 the patient underwent surgery. A right thoracotomy and a $4 \mathrm{~cm}$ longitudinal ocsophagotomy above the aortic arch were done. A big pedunculated multilobulated polyp, attached to the cervical oesophagus just below the upper oesophageal sphincter, was found and excised. The gross specimen (Fig. 3) was $14.5 \mathrm{~cm}$ long, had a maximum diameter of $7 \mathrm{~cm}$ and a $2 \mathrm{~cm}$ stalk. Its appearance was smooth and it had no ulceration on its surface. Histopathological analysis showed it to be composed of fibrous connective tissue with myxoid areas, a few fat cells, chronic inflammatory infiltrate and small congested vessels, and appearance typical of a fibrovascular polyp. ${ }^{\text {." }}$

The patient made an uneventful recovery and was seen again in November 1988 when he reported that he was completely free of dysphagia. His weight and routine blood tests had returned to normal. An upper gastrointestinal endoscopy showed no remnant of the polyp and a longitudinal scar at the site of the previous oesophagotomy. Erosive oesophagitis was grossly unchanged.
FVAI.UATION OF OESOPHAGEAI. FUNCTION Oesophageal manometry and $22 \mathrm{~h}$ intraoesophageal $\mathrm{pH}$ monitoring were performed before excision of the mass (May, 1988) and four months after (November, 1988). Oesophageal manometry was done using a low compliance pneumohydraulic infusion system (Sensormedics, Italy) at a flow rate of $0.5 \mathrm{ml} / \mathrm{min}$ and four external pressure transducers (Sensormedics 223651) connected to a polygraph (Sensormedics, model R711), permitting a response of $>200 \mathrm{mmHg} / \mathrm{sec}$." Lower and upper oesophageal sphincter activity were investigated using the slow pull through technique. The oesophageal body was assessed in two stages: at $3,8,13,18 \mathrm{~cm}$ and at 8,13 , $18,23 \mathrm{~cm}$ above the lower oesophageal sphincter. The most proximal port was placed in the cervical oesophagus just below the upper oesophageal sphincter. The average of data from all ports after wet $(5 \mathrm{ml})$ swallows was used to calculate amplitude and duration of the peristaltic wave. Twenty two hour intraoesophageal $\mathrm{pH}$ monitoring was performed following a protocol already reported in detail. ${ }^{2 n}$ Briefly, the test was done during hospital admission with an ambulatory system (Synectics, Sweden) using an antimony $\mathrm{pH}$ electrode placed $5 \mathrm{~cm}$ above the manometrically determined lower oesophageal sphincter. The electrode was thus positioned at a level where the lumen was filled with the mass. The patient had meals at 0800,1200 , and $1800 \mathrm{~h}$ and spent 13 hours in upright and nine hours in recumbent position. The tracing was analysed with respect to percentage of time at $\mathrm{pH}<4$ as a measure of gastrooesophageal reflux and with respect to percentage of time at $\mathrm{pH}>7$ as an index of alkalinisation of intraoesophageal environment. We have recently shown that intraocsophageal alkalinisation is not caused by reflux and it is presumably determined by the $\mathrm{pH}$ of swallowed fluids."

Preoperative ocsophageal manometry showed the lower oesophageal sphincter to have a basal tone of $6 \mathrm{mmHg}$ and apparent complete relaxations after swallows. The intraoesophageal baseline equalled the intragastric one. The oesophageal body did not show any pressure activity after 20 swallows (Fig. 4a). The patient was noted to belch after each wet swallow. Monitoring pressures in the hypopharynx and upper oesophageal sphincter during five additional wet swallows showed that the sphincter had a basal tone of $45 \mathrm{mmHg}$ and presented two complete relaxations after each swallow, separated by $3 \cdot()-3 \cdot 5 \mathrm{sec}$ one from the other. The first relaxation occurred normally just before the hypopharyngeal contraction and allowed the water to be swallowed. The second one allowed a belch to occur and was unaccompanied by pharyngeal contraction. Postoperative oesophageal manometry showed similar 


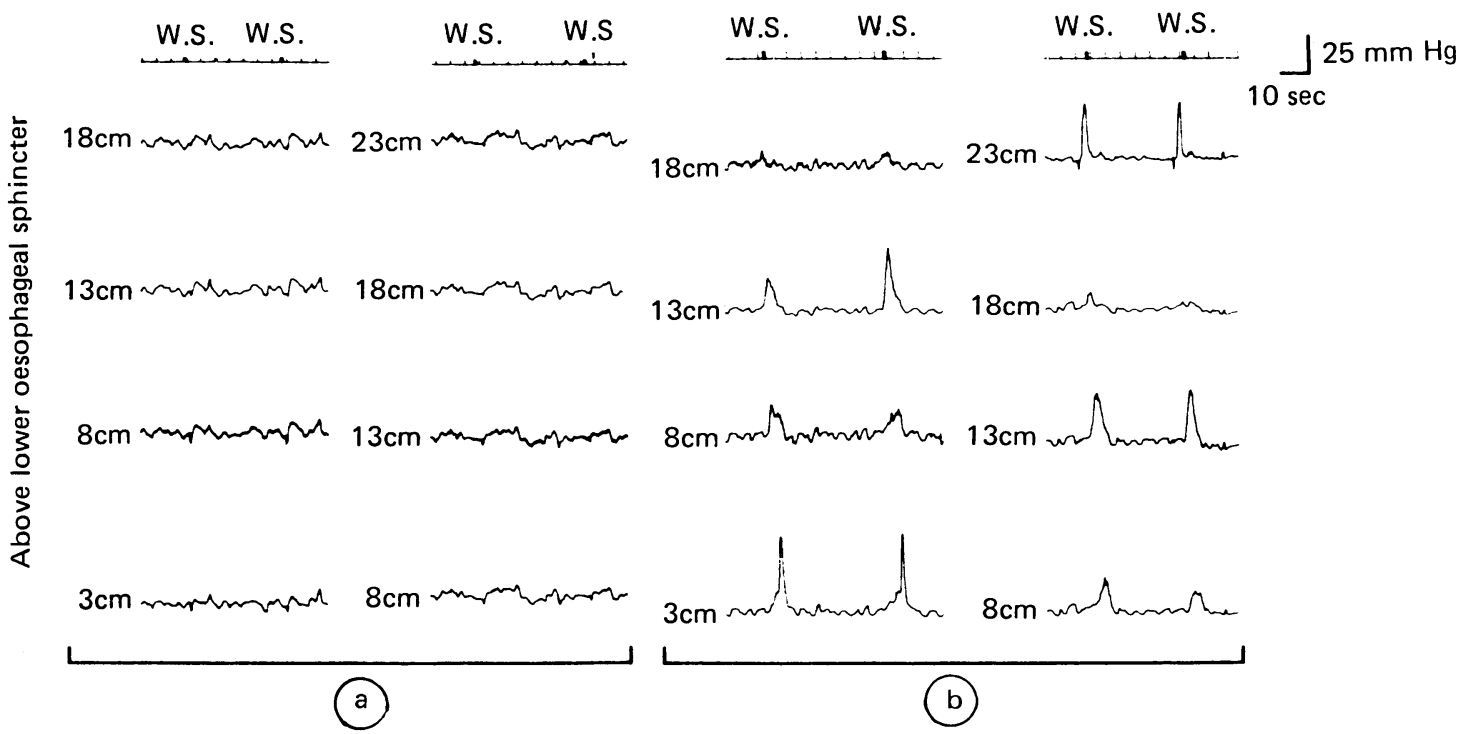

Fig. 4 Oesophageal manometry tracings: (a) before excision of the polyp: note complete absence of pressure activity; (b) four months after excision of the polyp. The port placed $23 \mathrm{~cm}$ above the lower oesophageal sphincter is within the cervical oesophagus just below the upper oesophageal sphincter. WS =wet swallow.

lower oesophageal sphincter function $(8 \mathrm{mmHg})$ and an intraoesophageal baseline $6 \mathrm{mmHg}$ less than the intragastric one. In the body, peristalsis was seen after 20 swallows with a median amplitude of 36 $\mathrm{mmHg}$ (range: $31-44 \mathrm{mmHg}$ ), a median duration of three seconds (range: $2 \cdot 4-3.2 \mathrm{sec}$ ) and a median volocity of $2.4 \mathrm{~cm} / \mathrm{sec}$ (range: $2 \cdot 2-3 \cdot 0 \mathrm{~cm} / \mathrm{sec}$ ) (Fig. 4b). The port situated $18 \mathrm{~cm}$ above the lower oesophageal sphincter, corresponding to the area of the oeseophagotomy, recorded very weak contractions $(<10 \mathrm{mmHg})$ only. The upper oesophageal sphincter showed a basal tone of $35 \mathrm{mmHg}$ and one complete relaxation after each swallow.

Preoperative $22 \mathrm{~h}$ intraocsophageal $\mathrm{pH}$ monitoring showed no acidification of intraoesophageal $\mathrm{pH}$, which in turn remained alkaline for $31.4 \%$ of total time $(60.3 \%$ in recumbent position). Post-operative $\mathrm{pH}$ monitoring revealed prolonged acid reflux, especially at night. Percentage of total time at $\mathrm{pH}<4$ was $16 \cdot 1$ ( 28.8 in recumbent position). In contrast, alkaline $\mathrm{pH}$ was recorded for only $1.6 \%$ of total time $(1.7 \%$ in recumbent position $)$.

\section{Discussion}

To our knowledge, about 60 cases $^{1-17}$ of giant fibrovascular polyp of the oesophagus have been reported in the literature. We describe an additional patient in whom the effects of the mass on oesphageal motility and $\mathrm{pH}$ were investigated. At preoperative mano- metry no pressure activity whatsoever was detected in the oesophageal body. Although we could not identify a reason for this alteration, three hypotheses, not mutually exclusive, may be proposed: first, a direct mechanical effect of the mass which may have absorbed the force generated by the oesophageal wall; second, a reflex inhibition of oesophageal motility triggered by oesophageal distention similar to previous findings in experimental conditions:?2:; and third, the effect of the increase in cylindrical bowel radius which, according to Young and Laplace's law, is inversely proportional to the intraluminal pressure generated by muscle contraction. Whatever the mechanism was, the alteration of motor function in presence of our polyp was reversible. Four months after excision of the mass the oesophagus had regained its normal size and peristalsis, although the amplitude of the pressure waves was at the lower limit of the normal range. ${ }^{24}$ Intraluminal pressures were still almost absent at the level of the oesophagotomy only, which was probably the result of the operation itself. The mechanism by which a benign tumour like the present one induces dysmotility seems to be different from that operating in malignant oesophageal tumours, according to a recent report..$^{2 n}$ In those cases dysmotility remained unchanged after laser ablation of the tumour and it was probably caused by intramural infiltration. The response of the upper oesophageal sphineter to wet swallows during the preoperative ocsophageal 
manometry was interesting. Conceivably, stasis of the swallowed water in the cervical oesophagus induced sudden distention of the oesophageal wall, which in turn triggered an upper oesophageal sphincter relaxation ${ }^{27}$ and consequently an oesophagopharyngeal gas reflux after each swallow.

Interpretation of $\mathrm{pH}$ monitoring data before operation should take into account that the $\mathrm{pH}$ electrode was placed at a level where the lumen was filled with the mass. Thus from our $\mathrm{pH}$ data it seems that on the one hand the polyp prevented gastric refluxate up the oesophageal lumen and on the other it grossly altered ocsophageal clearing, determining stasis of alkaline saliva and/or ocsophageal mucus.

Persistence of oesophagitis after excision of the tumour, prolonged reflux recorded postoperatively and heartburn in the medical history all suggest that crosive oesophagitis was unrelated to the tumour, but was instcad caused by coexisting gastrooesophageal reflux disease.

The absence of the polyp in the thoracic oesophagus at the barium swallow in 1973 and substantial increase in the size between 1986 and 1988 agree with a previous report which documented a visible polyp enlargement after one year of follow up."

It is interesting that a raised ESR, which was documented in our case and in previous ones, ${ }^{\mathrm{N} 14}$ may not necessarily suggest malignant degeneration of the polyp, but could simply be caused by inflammation within the tumour.

Finally, misdiagnosis of the pedunculated nature of the tumour has led to more complicated and hazardous surgical procedures than cervical approach and oesophagotomy on a few occasions ${ }^{1-2}$ " -11 (and our case) and even the additional use of computed tomography and magnetic resonance imaging scans have proved unhelpful" (and our case) in this respect. It seems clear to us after extensive revisions of the literature on oesophageal mass lesions, however, that a mass with the density of lax connective tissue at CT scan and filling most of the oesophagus cannot be anything but a giant fibrovascular polyp. Thus, as fibrovascular polyps are nearly always attached to the cervical oesophagus, oesophagotomy by the cervical route is the operation of choice even if the pedunculated nature of the mass is not apparent.

\section{References}

1 Chi PSH. Adams WE. Benign tumors of the esophagus. Arch Surg 195(): 60: 92-101.

2 Totten RS. Stout AP. Humphreys GH. Moore RL. Benign tumors and cysts of the esophagus. $J$ Thorac Cardiovasc Surg 1953: 25: 606-22.

3 Shmidt HW. Clagett OT. Harrison EG. Benign tumors and cysts of the esophagus. J Thorac Cardiovasc Surg $1961: 41: 717-32$.
4 Mackenzic M. A manual of diseases of the nose and throat. New York: William Wood and Company, 1884: 2: 68 .

5 Minski PR. Zur entwicklungsgeschichte und klinik der polypen und polypenahnlichen gewachse des rachens und der speiserohre. Dtsch Z Chir 1895; 41: 513.

$6 \mathrm{McBride}$ AF. Benign polypoid tumor of the esophagus. Cancer 1951: 4: 708.

7 Burrell M. Toffler R. Fibrovascular polyp of the esophagus. Dig Dis Sci 1973; 18: 714-8.

8 Liliequist B. Wiberg A. Pedunculated tumours of the ocsophagus. Acta Radiol [Diagn] 1974; 15: 383-92.

9 Venn GE, DaCosta P. Goldstraw P. Giant ocsophageal hamartoma. Thorax 1985; 40: 684-5.

10 Cole FH, Hays A. Tucker C. Giant esophageal fibrolipoma: case report and review of the literature. $J$ Tenn Med Assoc 1987; 80: 267-9.

11 Jang GC. Clouse ME, Fleischner FG. Fibrovascular polyp. A benign intraluminal tumor of the esophagus. Radiology 1969: 92: 1196-200.

12 Fuller AP. Clinical records. Pedunculated hamartoma of the ocsophagus. J Laryngol Otol 1963: 77: 706-13.

13 Allen MS. Talbot WH. Sudden death due to regurgitation of a pedunculated esophageal lipoma. $J$ Thorac Cardiovasc Surg 1967; 54: 756-8.

14 Lodmell L.A. Giant benign esophageal polyp. Gastroenterlogy 195.5: 29: 1077-82.

15 Lolley D. Razzuk MA, Urschel HC. Giant fibrovascular polyp of the esophagus. Ann Thorac Surg 1976: 22: 383-5.

16 Barki Y, Elias H, Tovi F, Bar-Ziv J. A fibrovascular polyp of the oesophagus. Br J Radiol 1981; 54: 142-4.

17 Patel J. Kieffer RW, Martin M. Avant GR. Giant fibrovascular polyp of the esophagus. Gastroenterology 1984: 87: 953-6.

18 Stout AP. Lattes R. Tumors of the esophagus. In: Atlas of tumor pathology. Washington DC: Armed Forces Institute of Pathology, 1957: 4(20): 25-32.

19 Penagini R. Bianchi PA. A case of primary achalasia associated with mid-thoracic esophageal diverticulum. $J$ Clin Gastroenterol (In press).

20 Penagini R. Al Dabbagh M. Misiewicz JJ, Evans PF, Trotman IF. Effect of dilatation of peptic esophageal strictures on gastroesophageal reflux. dysphagia, and stricture diameter. Dig Dis Sci 1988; 33: 389-92.

21 Penagini R, Yuen H. Misiewicz JJ. Bianchi PA. Alkaline intraocsophageal $\mathrm{pH}$ and gastro-oesophageal reflux in patients with peptic ocsophagitis. Scand J Gastroenterol 1988: 23: 675-8.

22 Chang PY, Hsu FY. The localization of the intestinal inhibitory reflex arc. Q J Exp Physiol 1942; 31: 311-8.

23 Andreollo NA, Thompson DG. Kendall GPN, Earlam RJ. Functional relationship between cricopharyngeal sphincter and oesophageal body in response to graded intraluminal distention. Gut 1988: 29: 161-6.

24 Kahrilas PJ. Dodds WJ. Hogan WJ. Kern M. Arndorfer RC. Rece A. Esophageal peristaltic dysfunction in peptic esophagitis. Gastroenterology 1986; 91: 897-9()4.

25 Richter JE. Wu WC. Johns DN, Blackwell JN. Nelson JL. Castell JA. Castell DO. Esophageal manometry in 95 healthy adult volunteers. Dig Dis Sci 1987: 32: $583-92$. 
26 Noar M. Fruchter G. Simko V. Abnormal esophageal motility due to esophageal carcinoma: a contributing factor to dysphagia [Abstract]. Gastroenterology 1988: 94: A326.
27 Kahrilas PJ. Dodds WJ. Dent J. Wyman JB. Hogan WJ. Arndorfer RC. Upper esophageal sphincter function during belching. (iastroenterology 1986: 91: 1.33-40. 